\title{
Determination of Leadership Factors That Influence the Development of Innovation in Intensive Software Systems through Literature Mapping
}

\author{
Pablo Alejandro Quezada- Sarmiento ${ }^{1}$, Monica Patricia Mayorga-Diaz, ${ }^{2}$, Renato Estuardo Paredes- \\ $\mathrm{Cruz}^{2}$, Maria Isabel Guaigua-Vizcaino ${ }^{2}$, Eva Ulehlova ${ }^{3}$, Patricia Marisol Chango-Cañaveral ${ }^{3}$, \\ Liliana Enciso ${ }^{3+}$ \\ ${ }^{1}$ Universidad Internacional del Ecuador - Escuela de Informática y Multimedia \\ ${ }^{2}$ Universidad Regional Autónoma De Los Andes “Uniandes"- Facultad De Sistemas Mercantiles \\ ${ }^{3}$ Universidad Tecnica Particular de Loja
}

\begin{abstract}
Innovation in software intensive systems has been increasing for several reasons: software is embedded in many sectors of the society; for this reason, the companies need to be knowledgeable about factors that affect the innovation to increase the development of their product success; the leadership is one of the factors, therefore, this research aim is to show the high-level groups in the context of innovation in leadership that influence on software intensive systems. Considering a big growth of software systems, it is important to analyze the human factor in the context of teamwork, leader and synergies of factors that can lead to a more innovative and successful software product. Furthermore, this paper shows the group level in the innovation and the influence on the development of software systems. As a research background literature review was used in order to support this paper. In the same sense there were determined the leadership factors in order to develop software intensive systems.
\end{abstract}

Keywords: innovation, software, leadership factors, literature mapping, software intensive systems.

\section{Introduction}

Software intensive systems formulate a new paradigm in software production that involves global computing systems such as the Internet or software services with emerging technologies based on embedded systems. Therefore, it is important to make visible the influence of leading factor of high-level groups. This paper will address the issue of innovation leadership factors in high-level teams that influence on the development of software intensive systems. This topic is essential due to the fact that allows us to have an insight of the high-level teams characteristics as well as of their leader, in addition, to determine which innovation factors influence the context of the software intensive systems. It is necessary to mention that in recent years there has been a significant development in the software intensive systems that nowadays are very common in a wide range of products and services.

It also analyses how the leaders personalities of the organization are related to the probability to innovate. Within the characteristics of the leader and the high-level team it is considered. The average age of the leader as well as of the group members, the average length of the company, level of education and heterogeneity, trends, educational level, work and the background. Likewise, it should be considered that the personal characteristics of the leaders influence how they make their decisions.

\section{Methodology}

\footnotetext{
${ }^{+}$Corresponding author.

E-mail address: paquezadasa@uide.edu.ec.
} 
In 2004-2005, Kitchenham, Dyba and Jørgensen wrote three articles suggesting the concept about evidence-based practice, which can be adopted in software engineering [1]. According to [2] the studies they use the same basic methodology of the Systematic Review of Literature (SLR), but they aim to identify and classify all research related to a subject of software engineering. This section describes and discusses the research methodology, used and led by systematic mapping, which includes the data collection technique and the method of data analysis. Systematic studies were conducted to assess the number and types of primary studies in an unbiased and systematic manner [3]. The systematic mapping study is a technique in evidencebased software engineering and has already been used in different subdomains of software engineering, software testing and specification requirements [4]. Systematic mapping requires good planning, execution and systematic analysis. Within the planning phase, the objective of the review was established, which was to identify the innovation leadership factors in the high-level groups and how they influence the development of intensive software systems.

In the same context, study selection criteria were used to identify primary studies that provide direct evidence about the research topic. In order to reduce the probability of bias, the selection criteria should be established during the protocol definition, although they may be refined during the research process [1], [3]. The selection of studies is a multi-step process. Initially, selection criteria should be interpreted freely, so that a study identified by electronic and manual searches can be clearly excluded based on the title and abstract [3]. A key part of systematic mapping is data extraction, in which essential text and data are obtained from the primary studies in an explicit and consistent manner according to a defined extraction strategy. However, before starting extraction, it is recommended to read the entire set of selected jobs at least once. The documents [1], [3], [5], [6] suggest:

- Publication data (eg, authors, year, title, source, abstract, objectives); Context descriptions (eg, topics, technologies, industry, adjustments).

- Findings.

According to [1], in a systematic mapping, it is fundamental to correctly identify, extract and synthesize information from included studies to provide reliable research responses, in this case focused on the evaluation of data by applying graphs. Once the data from the comprehensive studies had been extracted correctly, they were synthesized in order to provide new knowledge in the areas of research. In the same context, if information is available from ongoing studies, it can be obtained written permission and be available for researchers.

Among the questions to obtain information on the subject were:

RQ: What are the innovation leadership factors in software development teams?

Key terms for searches were. "Software and innovation", "Leading", "Group", "TMT", " Software Intensive Systems", "Education", "Source of Innovation", Group, Level ", SIS"”,," Agile"

The search was conducted in IEEE, ACM, Engineering Village, ScienceDirect, Ingenio, which was based on the keywords and data requested by each scientific database.

Another important factor was the quality of the information and its impact. Once the documentation was found, its classification was put onto lists; and the degree of relevance with respect to the topic was considered. In Figure 1, the aforementioned process is synthesized.

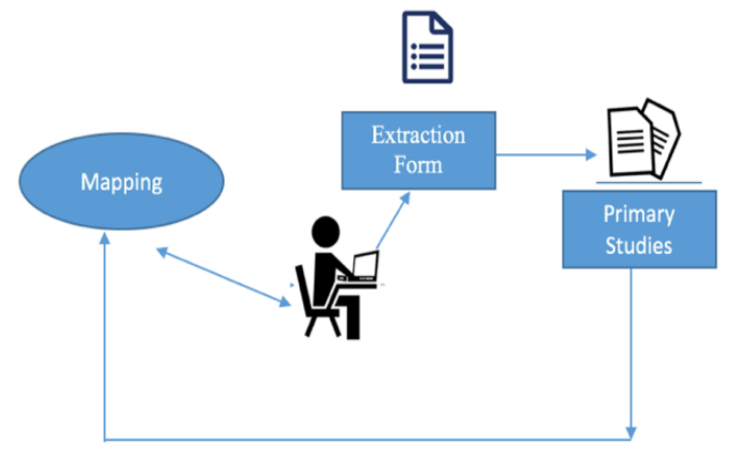

Fig. 1: General mapping process. 
In order to develop a synthesis of the data, it was necessary to take into account the identification of each primary study such as the name of the authors, the year of publication and the research criteria used in each database described above.

Within the conduction phase of the mapping, it was determined that articles were relevant and associated with the research. Once the basic documents were established, the reference frame was developed to determine the relevant results (See Fig.2).

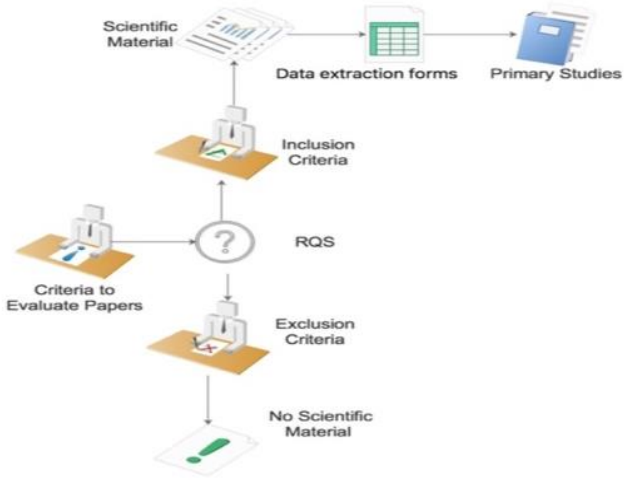

Fig. 2: Evaluation of primary studies.

\section{Relevant Result}

According to [7], CEOs as a factor for decision making that focuses on the senior management team as the unit of analysis. We assume this dominant coalition acts as an organizational decision-making unit. The decisions of special interest are those related to innovation.

One approach to leadership analysis is to evaluate innovation [8].

Functional Experiences and Environment. - Leaders with different background of functional experiences tend to vary in their attitudes, knowledge and perspectives [9]. Regarding the business environment, in which companies compete, may differ greatly, with hostile environments generating greater demand for innovation in some sectors [10].

Team work - According to [9]; a team can be defined as two or more people working in interdependence for a common purpose. Gathering a group of people does not create a "team". A team develops products that are the result of collective effort and involves synergy. Synergy is the property in which the total is greater than the sum of its parts

Team creation. - is the process of gathering the right people and having them work together for the benefit of a project. The team needs the "best and brightest" people, in order to succeed and they must be able to work together. When selecting team members, it is preferable to choose people who have many things in common and who are committed to accomplish the tasks.

-Enthusiastic.

-Optimistic

-Creative, flexible and open

-Positive.

It is important to emphasize that a good leader should:

-Work effectively as a member of a team.

-Treat with respect the values, beliefs and opinions of others.

-Communicate and interact effectively with people and groups.

-Willing to work towards common goals [10]

It is well-known that innovation is important around the world, and leadership style seems to influence innovation in different areas [11]. Benefits of innovation, such as software innovation, are not risk-free, as insufficient software innovation can cost shareholders and taxpayers billions of dollars each year. Even with 
the high risk and cost of software innovation, the Internet and software companies on average allocate a high proportion of research income and increase of 13\%. For innovation leadership to be reflected in the software development, factors such as project type, team structure and methodology should be considered [12].

Within the context of software development, it should be considered that it is characterized by team management and organized in a hierarchical structure with multiple layers of authority [11].

Team roles are based on functional tasks reflected by their organization, such as programmers responsible for programming, testers in charge of making tests, analysts responsible for analysis of requirements, etc. The work is delegated to the team members by their managers. Practices of traditional teams include documentation, specifications, and planning. There are indirect lines of communication across the different organizational hierarchies [10] [13].

In the context of agile software development methodology focuses on people and social interactions. Agile teams are meant to be democratic, teams where all members are considered equal, without a strict hierarchy in practice.

In agile development groups, members have the power to make collective decisions and show multifunctional skills, which increase their ability to organize themselves.

According to [14], [15] effective leaders motivate developers to ensure a successful and innovative product.

Using path-goal theory is based on leadership and motivation theories, in which a model is proposed and tested and it can be used to evaluate the relationship between the leadership style of a software project and the developers' motivation in order to contribute to the development of innovative software.

According to [16], [17], [18] there is a relationship between the transformational and transactional leadership styles and the commitment of innovation and its variables in companies in the commercial software industry. The study used a correlation design to obtain and analyse data from CEOs, managers and employees of software companies for the calculation of relationships.

The results provide insight into the relationships that can help companies in leadership training and recruitment, investment and leadership culture in software companies.

\section{Conclusions}

High-level groups should be set up under the premises of each industry. In the case of software, it must be adapted to the framework and methodology of the project, considering innovation as one of its basic foundations to achieve greater success in the market.

Innovation is one of the bases of the intensive software systems through which it makes the technology innovate according to the needs of the market, team Work in the software industry that include greater diversity of members with respect to education, age and ownership generate greater synergy in innovation processes.

\section{Acknowledgements}

The authors express their gratitude to Mgtr. Johanna Vanessa Vivanco Ochoa General Director of the Internacional University of Ecuador -Loja and Ph.D. Armando Gustavo Vega Delgado Research Director (Consejo de Investigación UIDE) for their constantly support.

\section{References}

[1] Fernandez, C., Daneva, M.; Sikkel, K.; Wieringa, R., Dieste, O. \& Pastor, O. (2009). "A systematic mapping study on empirical evaluation of software requirements specifications techniques", ESEM 3rd International Symposium, 502-505

[2] Kitchenham, B., \& Charters, S., (2007), "Guidelines for performing Systematic Literature Reviews in Software Engineering”, Technical Report, EBSE, IEEE. 
[3] Quezada, P., Garbajosa, J., Enciso, L. Use of standard and model based on BOK to evaluate professional and occupational profiles (2016) Advances in Intelligent Systems and Computing, 444, pp. 287-296. DOI: 10.1007/978-3-319-31232-3_27

[4] Quezada-Sarmiento, P. -., Enciso, L., \& Garbajosa, J. (2016). Use of body knowledge and cloud computing tools to develop software projects based in innovation. Paper presented at the IEEE Global Engineering Education Conference, EDUCON, 10-13-April-2016 267-272. 10.1109/EDUCON.2016.7474564

[5] Quezada-Sarmiento, P. A., Morocho-Quezada, M., Pacheco-Jara, L., \& Garbajosa, J. (2016). Evaluation of occupational and professional profiles in ecuadorian context based on guide of knowledge SWEBOK and ontological model. Paper presented at the 2016 3rd International Conference on eDemocracy and eGovernment, ICEDEG 2016, 42-47. 10.1109/ICEDEG.2016.7461694

[6] Hambrick, Donald C. and Phyllis A. Mason. 'Upper echelons: the organization as a reflection of its top managers', Academy of Management Review, 9, 1984, pp. 193-206.

[7] Quezada, P., Enciso, L., Garbajosa, J.Using tools of cloud computing for defining, planning, monitoring innovation projects and knowledge generation [Uso de herramientas de computación en la nube para definir, planificar, controlar proyectos de innovación y generación de conocimiento] (2015) XI Jornadas Iberoamericanas de Ingenieria de Software e Ingenieria del Conocimiento, JIISIC 2015, pp. 121-131.

[8] Miller, R. A. 'Current occupation and past training of adult workers'. Office of Statistical Standards, Statistical Evaluation Report, Bureau of the Budget. Top Management and Innovations in Banking 123 Washington, DC: U.S. Government Printing Office, 1968.

[9] Quezada-Sarmiento, P. -., Enciso-Quispe, L. -., Garbajosa, J., \& Washizaki, H. (2016). Curricular design based in bodies of knowledge: Engineering education for the innovation and the industry. Paper presented at the Proceedings of 2016 SAI Computing Conference, SAI 2016, 843-849. 10.1109/SAI.2016.7556077

[10] Quezada-Sarmiento, P. A., \& Mengual-Andrés, S. (2018). Promoting innovation and skills entrepreneurship in training professionals in software engineering: A focus on academy and bodies of knowledge context. [Fomento de la innovación y competencias de emprendimiento en los profesionales en formación en Ingeniería de Software: Un enfoque de la academia y Cuerpos de Conocimiento] Espacios, 39(6)

[11] J.E. Tomayko and O. Hazzan, Human Aspects of Software Engienering. Charles River Media, 2004.

[12] Eras, A.G., Quezada, P.S., González, P.L., Gallardo, C. Comparing competences on academia and occupational contexts based on similarity measures (2015) WEBIST 2015 - 11th International Conference on Web Information Systems and Technologies, Proceedings, pp. 540-546

[13] Li-Ren Y.; Chung-Fah H.; Kun-Shan; W. (2010); “The association among project manager's leadership style, teamwork and project success"

[14] Yan; L.; Chuan-Hoo; T. \& Hock-Hai; T.; (2012);" Leadership characteristics and developers' motivation in open source software development”; Elsevier ;Recuperado de: Information \& Management Journal home page: www.elsevier.com/locate/im

[15] Bantel, K. A. and Jackson, S. E. (1989). 'Top management and innovations in banking - does the composition of the top team make a difference'. Strategic Management Journal, 10, 107-24.

[16] Delgado F. (2004), SOBRE EL CONCEPTO Y EL ESTUDIO DEL LIDERAZGO POLÍTICO. Una propuesta de síntesis, Psicología Política, No 29, 2004, 7-29

[17] Hamid; T. (2011) “Teamwork productivity \& effectiveness in an organization base on rewards, leadership, training, goals, wage, size, motivation, measurement and information technology"; ScienceDirect WWW.sciencedirect.com

[18] Quezada-Sarmiento, P. A., \& Mengual-Andrés, S. (2017). Implementation of a web and mobile solution for vehicular management based on aspects architecture and agile methodologies: An educational approach from theory to practice. [Implementación de una solución web y móvil para la gestión vehicular basada en Arquitectura de Aspectos y metodologías ágiles: Un enfoque educativo de la teoría a la práctica] RISTI - Revista Iberica De Sistemas e Tecnologias De Informacao, 2017(25), 98-111. 10.17013/risti.25.98-111 